\title{
Relato da pesquisa científica de oftalmologia - o emprego de terminologias greco-latinas
}

\author{
Scientific report in ophthalmology - the use of Greek and Latin words
}

Edmea Rita Temporini ${ }^{1}$ José Carlos Eudes Carani²
Trabalho realizado na Faculdade de Medicina da Universidade de São Paulo - USP - São Paulo (SP) - Brasil.

${ }^{1}$ Livre-docente de Metodologia Científica, Assessora de Pesquisa junto à disciplina de Oftalmologia da Faculdade de Medicina da Universidade de São Paulo - USP São Paulo (SP) - Brasil.

${ }_{2}^{2}$ Coordenador do Curso de Especialização em Oftalmologia do Hospital CEMA. Médico Assistente Doutor da Clínica Oftalmológica do Hospital das Clínicas da Faculdade de Medicina da USP - São Paulo (SP) - Brasil.

Endereço para correspondência: Edméa Rita Temporini. Av. Piassanguaba, 2.900 - São Paulo (SP) CEP 04060-004

E-mail: ertempor@usp.br

Recebido para publicação em 02.04.2009

Última versão recebida em 19.01.2010

Aprovação em 20.01.2010

\begin{tabular}{|l|}
\hline RESUMO \\
\hline A pesquisa de conhecimentos no campo da oftalmologia constitui \\
processo dinâmico que requer divulgação, em especial por meio de \\
relatos escritos. A redação científica vale-se da terminologia greco- \\
latina. Discutem-se aspectos referentes à clareza, objetividade e pre- \\
cisão da escrita e oferece-se glossário sucinto desses termos aplicados \\
a textos científicos.
\end{tabular}

Descritores: Oftalmologia; Relatórios de pesquisa; Redação; Terminologia

\section{INTRODUÇÃO}

O oftalmologista interessado na descoberta e divulgação de novos conhecimentos no seu campo de atuação deve familiarizar-se com certos termos eruditos, de raízes gregas e latinas, empregados nos textos científicos. A abolição do ensino do latim nas escolas brasileiras, efetuada há algumas décadas ${ }^{(1)}$ dificultou a compreensão desses termos aplicados também à área da medicina e das ciências em geral. Na atualidade, o idioma grego somente é ensinado em estudos avançados e núcleos religiosos. Assim, espera-se que o presente texto possa contribuir na tarefa de preparação do pesquisador para o planejamento, elaboração e divulgação do conhecimento científico buscado na área de oftalmologia. Buscou-se centrar os aspectos etimológicos, mais especificamente, à escrita científica referente ao relato de pesquisas oftalmológicas que, dessa forma, constitui o eixo central da organização dos conteúdos apresentados.

\section{O enfoque metodológico}

Todo projeto de pesquisa científica inclui etapas distintas: planejamento, coleta de dados, análise e interpretação dos resultados e relato escrito do que foi realizado ${ }^{(2)}$. Cada uma destas etapas abrange procedimentos estratégicos e técnicos que buscam revelar, afinal, algum conhecimento novo ou reforçador acerca da realidade investigada. Para tal, é necessário haver interdependência dos diversos procedimentos, de forma a estabelecer o encadeamento lógico que conduza na obtenção da verdade probabilística dos fatos estudados. A ordenação adotada obedece a determinado rumo (do grego "methodos" = procura atenciosa, busca), ou seja, às regras do método científico selecionado para realizar aquele estudo específico.

As diversas modalidades da pesquisa científica, sejam experimentais ou observacionais, apresentam importância na medida em que identificam e divulgam novas informações, especialmente a profissionais distantes dos grandes centros. A divulgação de qualquer conhecimento 
contribui para elevar o senso crítico e produzir ciência ${ }^{(3)}$. Em geral, decorre da publicação de artigos em periódicos científicos e/ou de livros especializados.

A obtenção do conhecimento científico revela-se essencial para o progresso da ciência e da prática em oftalmologia. Necessário torna-se compreender e controlar agentes responsáveis por afecções e distúrbios oculares que conduzem à incapacidade visual e à cegueira. Não menos importante é a busca do aumento da eficiência dos serviços oftalmológicos utilizando conhecimentos advindos da pesquisa operacional. Ou, ainda, a necessidade de compreender fatores humanos imbricados na ocorrência, prevenção, agravamento e tratamento de distúrbios do sistema visual ${ }^{(4)}$.

A etapa final do projeto de pesquisa consiste em relatar o que foi realizado, apontando as minúcias do caminho percorrido, até a obtenção das conclusões.

Nenhum projeto científico pode-se considerar terminado, até que seja redigido o relatório da pesquisa ${ }^{(5)}$. Esta é a forma de divulgar novos conhecimentos à comunidade científica e instituições interessadas. Constitui-se em atribuição dos pesquisadores que, assim, tornam conhecidos seus resultados, podendo ser conferido crédito adequado à investigação completada.

O relato da pesquisa oftalmológica pode apresentar diferentes formatos conforme as finalidades e os leitores a que se destina ${ }^{(5-8)}$. A escrita científica sempre deve fornecer explicações; para tal, constituem questões básicas a norteá-la:

- quem são (ou serão) os leitores?

- o que precisam saber, em termos da informação, explicação e exemplos?

- o que foi estudado?

- com que finalidade?

- o que foi realizado e como?

- o que foi descoberto (ou identificado)?

- o que foi concluído? ${ }^{(6)}$

Uma tese ou dissertação não só comunica estratégia e resultados da pesquisa, mas também serve de fonte de consulta nas bibliotecas. Por isso, são trabalhos longos em geral e ricos em detalhes.

Os artigos de periódicos, por sua vez, constituem relatos curtos, devido ao fato de serem restritos ao espaço para publicação e às normas das revistas científicas, além de se destinarem a profissionais ocupados, que dispõem de tempo limitado para a leitura ${ }^{(9)}$.

Essas diferenças explicam a quantidade de detalhes presentes em um ou outro tipo de relato $^{(7,10)}$.

\section{Características da escrita científica}

Quanto ao estilo, esse tipo de redação contrapõe-se a algumas regras da boa escrita aprendidas desde os primeiros anos escolares. Deve-se evitar a associação de idéias, a imaginação, a linguagem ambígua e figurada, o uso de sinônimos. Sua força provém da comunicação clara, simples e objetiva das idéias $^{(6)}$.
A clareza do pensamento aplicada ao método da pesquisa, desde o planejamento até a execução, reflete-se certamente na clareza do seu relato escrito ${ }^{(11)}$. Para tal, evite-se o emprego de muitas palavras em apenas uma frase. Decide-se o que deve ser comunicado e redige-se de forma direta. As sentenças devem ser breves e conter apenas um pensamento, redigido de forma completa. Quanto mais simples o estilo da escrita, melhor o seu entendimento.

A precisão e clareza do relato escrito dependem da escolha e emprego das palavras que devem descrever o que foi realizado, em todas as fases do estudo ${ }^{(10)}$. Da qualidade desse relato dependem a compreensão correta da investigação e a possibilidade de sua replicação. Vale reforçar que toda pesquisa deve ser replicável, assim como toda conclusão, passível de ser verificada. Ademais, a escrita deve estar isenta de erros e omissões, não obstante devam ser mencionadas as limitações do estudo(12).

A precisão diz respeito também a se evitar o emprego de termos indefinidos referentes à quantidade, qualidade e frequência. É impreciso escrever "muitos", "poucos", "frequentemente", "raramente", "bom", "mau”. Essas palavras refletem a subjetividade do pesquisador, calcada em parâmetros pessoais que não podem ser compartilhados pelo leitor do relato ${ }^{(7,10)}$.

A precisão da escrita deve oferecer ao leitor todos os elementos necessários a sua compreensão - o leitor não deve ser compelido a imaginar. Por essa razão, os dados devem ser apresentados de forma direta, específica e suficientemente clara, visando eliminar qualquer perigo de falsa interpretação. Qualquer suposição, afirmação ou generalização deve ser baseada em evidência suficiente e estar de acordo com o que foi verificado.

$\mathrm{Na}$ ciência, as afirmações (ou negações) devem ser objetivas - baseadas nas evidências - e não subjetivas - baseadas na imaginação ou em opiniões não comprovadas.

Para tal, constituem interrogações importantes: o pesquisador considerou a evidência suficientemente? Existem evidências suficientes que explicam o fato? Em caso negativo, observações posteriores devem ser recomendadas mediante a realização de futuros estudos ${ }^{(6,13)}$.

Como se pode depreender dos aspectos apresentados, a forma e o emprego da terminologia detêm função fundamental na escrita científica. Entre os fatores determinantes dessa importância, situa-se a contribuição oferecida pela compreensão da origem da terminologia empregada, de suas raízes gregas e latinas, facilitando o emprego correto e o entendimento mais abrangente. Nesse sentido, abordam-se algumas explicações etimológicas de termos latinos e gregos empregados usualmente no universo da metodologia científica, buscando oferecer subsídios aos interessados. Com essa intenção, apresenta-se a seguir, um glossário sucinto, na qualidade de instrumental facilitador às regras da escrita científica. Vale reiterar que grande parte dessa terminologia aparece na literatura científica mantendo a forma original, do grego ou do latim. 
Terminologias grega e latina aplicadas à pesquisa científica - Glossário ${ }^{(14-16)}$

\section{Etimologia}

"Etymon", em grego, significa: "sentido verdadeiro"; de étymos "verdadeiro, certo, real".

Etimologia é a parte da gramática que se dedica ao estudo (logia) da origem das palavras.

Ad hoc: "para isto" ou "para esse fim". Consultor "ad hoc" é designado para determinada tarefa de consultoria científica.

Aleatório: do latim "aleatorius" (jogo); "aleator, aleatoris" (jogador) e Alea (jogo de dados, sorte). Que depende das circunstâncias, do acaso, casual fortuito.

A posteriori: de trás para diante. Argumentar "a posteriori" é argumentar passando do efeito à causa.

A priori: de frente para trás, anteriormente à experiência. Em instrumento de pesquisa é comum categorizar variáveis "a priori”, sem conhecer os dados.

Apud: junto a. Preposição latina usada em bibliografia antes do nome de um autor, para indicar citação indireta.

Caput: parágrafo, capítulo. É a cabeça, título, aplicável a um quadro ou tabela ou à parte de um texto.

Circa: aproximadamente, ao redor de. Refere-se a dados aproximados.

Conditio sine qua non: condição sem a qual não... Trata-se de condição necessária a algum fato, evento ou circunstância.

E.g.: abreviatura de "exempli gratia", que significa "por exemplo".

Errata: coisas erradas, erros. Nome habitual da lista de erros tipográficos com as respectivas correções.

Et alii: e outros. Usado para citação bibliográfica, quando, além do autor indicado, há co-autores. Abreviado por et al.

Et caetera ou et cetera: e as demais coisas. Geralmente abreviado por etc.

Empírico: do latim "empiricus", do grego "empeirikos". Experimentado, que se guia pela experiência. Método que se apoia na experiência e na observação e não sobre dados científicos.

Experientia: do latim "experientia", de "experiri". Fazer o ensaio ou prova de...

Fac símile: faz igual. Indica reprodução fotográfica de texto manuscrito, mecanografado ou impresso.

Grosso modo: de modo grosseiro, aproximadamente.

Honoris Causa: para a honra. Diz de título conferido sem exame, à guisa de homenagem (doutor honoris causa).

Ibidem: no mesmo lugar. Termo usado em bibliografia no sentido de "na mesma obra, capítulo ou página". Abreviatura: ibid

Idem: o mesmo, a mesma coisa, da mesma forma. Em bibliografia, "o mesmo autor".

Id est: isto é.

In: em. Usado em bibliografia antes do título de obra que serve de fonte a uma citação.

Infra: abaixo. Termo de bibliografia para indicar trecho da mesma página, mais abaixo, ou das páginas posteriores.
In loco: no mesmo lugar, no próprio lugar. O mesmo que "in situ".

In situ: "no (próprio) lugar"; "no lugar onde estava".

In totum: integralmente.

Ipsis litteris: com as mesmas letras, isto é, "nos mesmos termos", "textualmente". O mesmo que "ipsis verbis".

Ipsis verbis: refere-se a palavras faladas. Com as mesmas letras.

Lapsus linguae: lapso da língua, erro involuntário cometido na conversação.

Lato sensu: em sentido amplo. Antônimo: "stricto sensu".

Método: do grego "methodos" - procura atenciosa, busca, perseguição: formado de "metá" (através) + "hodós" (caminho). A maneira, procedimento ou técnica sistemática na realização de detalhes de uma operação, testes, tratamento ou de qualquer ato.

Metodologia: do grego "méthodos" + "hodós" + "lógos" (argumento, discurso, narração). O sistema de princípios e procedimentos utilizados nos empreendimentos científicos.

Mutatis mutantis: mudado o que deve ser mudado, isto é "feitas as modificações necessárias", ou, ainda, "com a devida alteração de pormenores".

Opere citato: na obra citada. Emprega-se para citar obra já citada antes; abreviatura: o.c.

Pari passu: "a passo igual", "acompanhando lado a lado", "a par".

Per se: "por si"; "naturalmente".

Post scriptum: pós-escrito.

Pro forma: "por (mera) formalidade", formalmente.

Quasi: "como se fosse à maneira de, à semelhança de". Quasiexperimento é a denominação dada a uma modalidade de pesquisa.

Quantum satis: quanto basta. Antiga fórmula de farmácia, até hoje usada em receitas sob a forma abreviada q.s.

Quod vide: veja isto. Fórmula para remeter para outro verbete da mesma enciclopédia ou dicionário. Abreviatura: q.v.

Sic: assim. Palavra que se pospõe entre parênteses a uma citação para indicar que, por errado ou estranho que pareça, o texto original é assim mesmo.

Sine die: sem dia marcado, sem fixar data.

Sine qua non: condição sem a qual não...

Stricto sensu: em sentido restrito. Antônimo: "lato sensu".

Sui generis: de seu próprio gênero. Diz-se de pessoa ou coisa peculiar, que não apresenta semelhança com ninguém ou nada. Supra: acima. Termo de bibliografia para indicar trecho da mesma página, mais acima, ou de páginas anteriores.

Teoria: do grego "theos" (deus) + "oros" (que vigia, observador). Série de leis que servem para relacionar determinada ordem de fenômenos. Termo derivado de "theorós", pessoa enviada para consultar um oráculo, donde o verbo "theoréo" - "recorrer ao oráculo" e depois "contemplar". Em grego, "theoria" significa primeiramente o envio para consultar orá- 
culo e, posteriormente, entre os filósofos, "visão" e "teoria"; passou ao latim "theoria" (especulação).

Versus: contra.

Vice versa: em sentido oposto, ao contrário, ou reciprocamente. Aportuguesado, escreve-se com hífen.

Não se pretendeu esgotar o universo de possibilidades do emprego de terminologia greco-latina no campo da pesquisa científica, mas sim, procurou-se apresentar, seletivamente, alguns dos termos mais comumente observados na literatura, conferindo-lhes o significado apropriado. Espera-se, dessa forma, contribuir para a clareza, precisão e adequação da escrita científica que deverá refletir os modos de pensar e agir do pesquisador, no desenvolvimento e divulgação do seu estudo.

\section{ABSTR ACT}

Scientific research in ophthalmology is a dynamic process usually delivered by means of written reports. Greek and Latin words are commonly used in scientific writing. This paper points out some issues related to the clarity, objectivity and precision of writing and offers a short glossary of terms from Greek and Latin languages which are commonly used in scientific writing.
Keywords: Ophthalmology; Research reports; Writing; Terminology

\section{REFERÊNCIAS}

1. Viaro ME. Por trás das palavras. Manual de etimologia do Português. São Paulo: Globo; 2004

2. Hulley SB, Cummings SR, Browner WS, Grady D, Hearst N, Newman TB. Delineando a pesquisa clínica: uma abordagem epidemiológica. $3^{\underline{a}}$ ed. Porto Alegre: Artmed; 2005.

3. Campos MSQ. Pesquisa básica. Arq Bras Oftalmol. 1997;60(5):453.

4. Temporini ER, Kara-José N. Níveis de prevenção de problemas oftalmológicos propostas de investigação. Arq Bras Oftalmol. 1995;58(3):189-92.

5. Day RA. Como escribir y publicar trabajos científicos. Washington DC: Organizacion Panamericana de la Salud; 1990. (Publicacíon cientifica, 512)

6. Barrass R. Scientists must write. $2^{\text {nd }}$ ed. London: Routledge; 2006.

7. Polit DF, Hungler BP. Nursing research: principles and methods. 3rd ed. Philadelphia: Lippincott; 1987.

8. Katchburian E. From thesis to publication of a paper: some ideas and suggestions. Arq Bras Oftalmol. 1999;62(1):8-9.

9. Bicas HEA. Publicações científicas. Arq Bras Oftalmol. 1999;62(5):549.

10. Costa VP. Aspectos principais da análise de um trabalho. Arq Bras Oftalmol. 2003;66(Supl 6):7-10.

11. Azeredo AP. O método científico. Rio de Janeiro: UFRJ; 2002

12. Souza-Dias CR. Erros vernáculos mais frequentemente cometidos no meio médico-acadêmico - parte I. Arq Bras Oftalmol. 1999;62(3):229-33.

13. Davis M. Scientific papers and presentations. $2^{\text {nd }}$ ed. San Diego, Califórnia: Elsevier; 2005

14. Bailly A. Dictionnaire grec-français, Paris: Librairie Hachette; 1950.

15. Gaffiot F. Dictionnaire illustrè latin-français. Paris: Librairie Hachette; 1937.

16. Rónai P. Não perca o seu latim. Rio de Janeiro: Nova Fronteira; 1980.

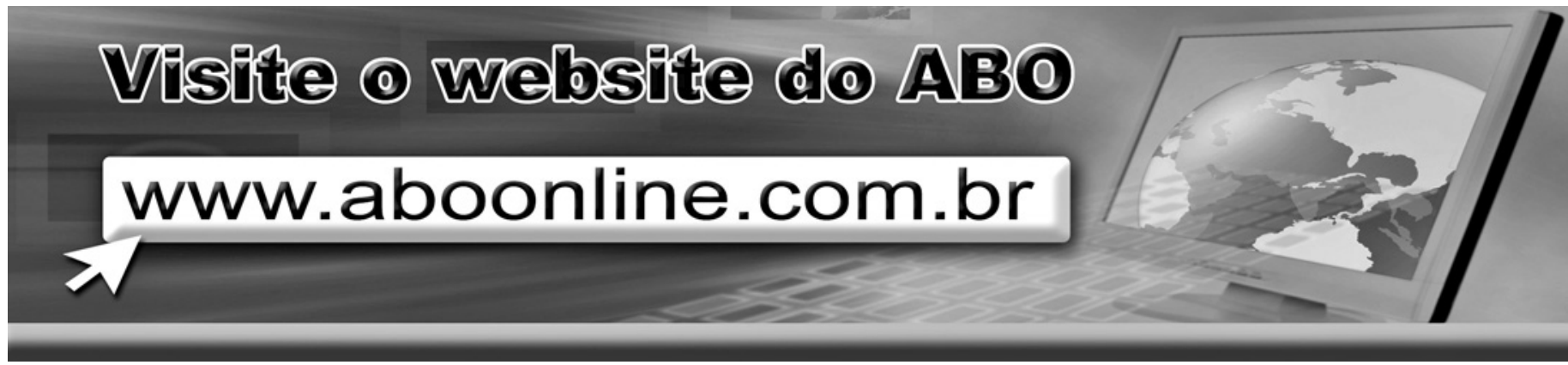

